\title{
Fast \& Energy Efficient Start-up of Crystal Oscillators by Self-Timed Energy Injection
}

\author{
J.B. Lechevallier, Student Member, IEEE, R.A.R. van der Zee, Member, IEEE, B. Nauta, Fellow, \\ IEEE
}

\begin{abstract}
Crystal oscillators take a long time and, more importantly, a significant amount of energy to start-up. This paper presents a self-timed energy injection technique to quickly startup a crystal oscillator, for a very low energy consumption. This is achieved without a power-hungry oscillator to provide the injection signal. The design considerations are discussed, and a prototype crystal oscillator using the proposed technique is integrated in a 22nm FD-SOI technology.

Connected to a $50 \mathrm{MHz}$ crystal, the manufactured IC achieves a start-up time of $6 \mu \mathrm{s}$, for an energy consumption of just $3.7 \mathrm{~nJ}$.
\end{abstract}

Index Terms-Crystal oscillators, energy injection, Internet of Things, start-up energy, start-up time, low power, duty cycling

\section{INTRODUCTION}

$\mathrm{L}$ OW-POWER wireless systems are on the rise, with applications in IoT such as Bluetooth Low Energy (BLE). Supply energy is usually scarce in these applications as power is often delivered by batteries or energy harvesting, necessitating techniques to achieve low power consumption. Duty cycling is one way to achieve low (average) power consumption. A duty cycled system spends most of the time in a low-power sleep mode, only briefly waking up to transmit or receive packets in the active mode [1]. The transition from sleep mode to active mode requires starting up the radio circuit blocks, which take some time for settling. Most circuit blocks, such as the LDO and PLL, settle quickly (tens of $\mu$ s range) [2]. However, the crystal oscillator that serves as frequency reference conventionally starts up relatively slowly (ms range) [3]-[7] due to the high quality factor of the crystal resonator. The start-up of this crystal oscillator not only dominates overall start-up time but-more importantly-comes with a large energy consumption, gravely compromising battery life. This paper presents a technique to quickly start up crystal oscillators with very low energy consumption.

A typical crystal oscillator is shown in Fig. 1. The RLC model of the crystal models the fundamental resonance mode by a series (motional) branch consisting of $L_{m}, C_{m}$ and $R_{m}$, in parallel with the package parasitic capacitance $C_{p}$. During startup, the amplitude $\hat{I}_{m}$ of the sinusoidal series branch current $I_{m}(t)$ grows from its initial value $I_{m}(0)$ to its steady-state amplitude $\hat{I}_{m, S S}[8]$. Conventionally, the oscillation is started

This work was supported by STW, the Dutch Technology Foundation, project no. 13769. J.B. Lechevallier, R.A.R. van der Zee and B. Nauta are with

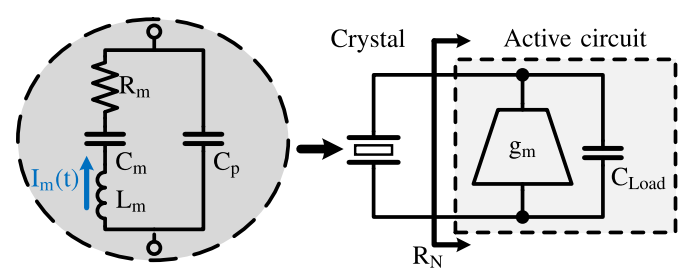

Fig. 1. Generic crystal oscillator

and sustained by an active circuit, as shown in Fig. 1. This circuit provides a complex impedance, consisting of an imaginary part, formed by $C_{\text {Load }}$ as specified by the crystal manufacturer, and a negative real part, usually called the negative resistance $R_{N}$, which compensates the crystal losses. Since the initial condition is typically very small (noise), and the magnitude of the negative resistance is quite small, start-up is typically a lengthy and inefficient process. Recent literature has presented solutions that improve the start-up time and/or energy consumption by injecting energy into the crystal before settling to the steady state [8]-[15] and/or increasing the magnitude of the negative resistance during start-up [3], [10], [13], [16], [17].

The magnitude of the negative resistance can be boosted by increasing $g m$ [10], [13], [16]-[19] and/or altering the load capacitance $C_{\text {load }}$ [16], [20]. However, the maximum negative resistance, and hence minimum start-up time, is limited by $C_{p}$ [10], [13], [17]-[19]. This can be overcome by making the active circuit appear slightly inductive to (partially) cancel $C_{p}$ [13], [17]. Although this solution is among the most energyefficient in literature, the start-up time is still relatively long, as perfect cancellation of $C_{p}$ over PVT variations is difficult.

Another way to reduce the startup time is energy injection [8][15]. During start-up, an injection oscillator is connected to the crystal, as shown in Fig. 2. The injection oscillator injects energy at the frequency of the crystal. Fig. 3 shows an example of a square-wave injection waveform and the resulting growing amplitude of $I_{m}$. Provided that the crystal quality factor is high ( $R_{m}$ is small), the amplitude $\hat{I}_{m}$ can be calculated to (initially) increase linearly over time with a slope of $\frac{A}{2 L_{m}}[21]$, where $A$ is the amplitude of the fundamental of the injection waveform [8], [10]. Although the repetitive (dis)charging of $C_{p}$ introduces significant $C V^{2}$ losses, the start-up slope is not dependent on $C_{P}$, as opposed to negative-resistance based circuits.

the Integrated Circuit Design Group, University of Twente, 7522NB Enschede, The Netherlands. (email: r.a.r.vanderzee@utwente.nl) 


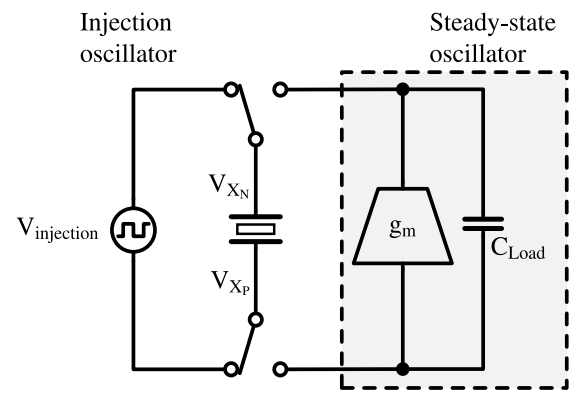

Fig. 2. Energy Injection concept
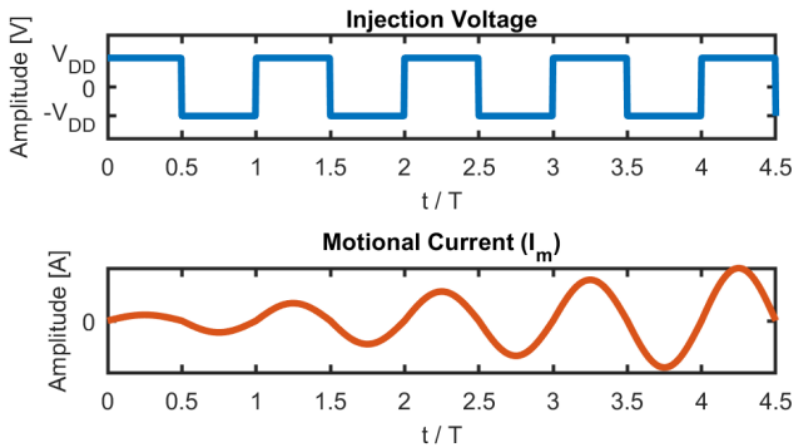

Fig. 3. Ideal Energy Injection waveforms

However, a major challenge in energy injection techniques is the accuracy of the injection oscillator. To be effective, the injection signal should be in phase with the current waveform over the entire injection time. Since the start-up takes at least hundred(s) of periods, this puts tough requirements on the frequency accuracy of the injection oscillator, i.e. better than $0.5 \%$, over PVT variations [9]. To achieve the required accuracy, prior art has resorted to measures such as calibration or trimming [8], [11], [12], chirping [10], [13], dithering [9] or injecting in multiple steps [14], [15]. Calibration attempts to exactly track the crystal frequency, which is power consuming and difficult to ensure over PVT. Chirping and dithering spread the energy over a frequency band, such that there is always a certain amount of energy injected in the crystal, even with frequency uncertainty due to PVT variations. However, this also reduces the amount of energy into the crystal, such that it takes a longer time to reach the steady state amplitude. Injecting over multiple steps in time reduces the frequency accuracy requirements on the injection oscillator, since the injection signal only needs to be in phase with the crystal oscillation for a short time. On the other hand, additional time and circuitry is necessary to synchronize the injection signal with the crystal oscillation. The lowest startup time with energy injection can be obtained if the injection duration $T_{\text {injection }}$, is precisely timed as to inject the exact amount of energy into the crystal that is required to reach the steady state amplitude [8]. However, the generation of the injection signal requires frequency tuning to the specific crystal.

This paper proposes a self-timed energy injection technique that allows quick and energy efficient start-up of crystal oscillators, without the use of an injection oscillator. This is achieved by realizing that the injection waveform, as shown in Fig. 3, ideally switches polarity at each zero-crossing of the current. Instead of relying on an injection oscillator to generate the timing, the zero crossings can be directly detected to generate a self-timed injection signal.

Section II further elaborates on the concept of self-timed energy injection. Section III covers the circuit implementation and section IV shows simulation results. Measurement results on a prototype are described in section $\mathrm{V}$, followed by a conclusion in section VI.

\section{SELF-TIMED ENERGY INJECTION}

\section{A. Concept}

The proposed self-timed energy injection relies on measurement of the motional current $I_{m}$. To minimize $C V^{2}$ losses, there are no load capacitors connected during start-up. It is impossible to directly measure $I_{m}(t)$ since the motional branch is in parallel with $C_{p}$, so any current measured at the crystal terminals could flow in either the motional branch or $C_{p}$. This can be overcome by ensuring that no current flows in $C_{p}$, such that the current measured at the crystal terminals can only flow through the motional branch. This is achieved by applying (quasi-) constant voltages to the crystal by connecting it in an H-bridge, as shown in Fig. 4. For a zero switch resistance, the voltage over the crystal settles immediately to $+V_{D D}$ or $-V_{D D}$, respectively. This means that $\frac{d V_{C_{p}}}{d t}=0$ (except at the switching instants), meaning that $I_{C_{p}}=0$, and hence all current $I_{m}$ flows through the low-impedance path to the supply. The switch current therefore accurately indicates the zero-crossing of $I_{m}$.

The current measurement can be performed by exploiting the non-zero on-resistance of practical switches. The voltage over a switch in 'on' state is a measure of the current flowing through it. The use of non-zero switch resistances has some implications that will be further discussed in the next subsection.

A block diagram of the proposed architecture is shown in Fig. 5. The switches to ground have a low impedance, while the switches to the supply have a relatively high resistance to increase the current detection sensitivity. As $\hat{I}_{m}(t)$ is normally very small before start-up, it is maximized by applying a single voltage step, leading to an initial oscillation which is large enough to be detected. Comparators determine the direction of the current through the switches, while only the comparator that is connected to the switch that is 'on' is active. If the output of that comparator toggles, its input voltage has changed sign, meaning that $I_{m}$ has reversed direction. The switch control block then toggles the switches, and waits until the next zero crossing is detected, resulting in current and voltage waveforms similar to Fig. 3. 


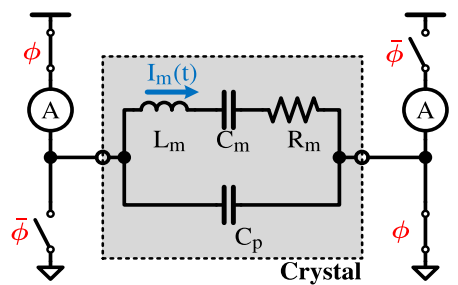

Fig. 4. Self-timed energy injection concept

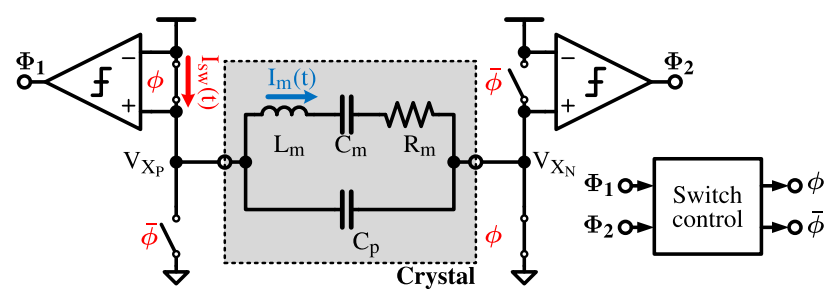

Fig. 5. Self-timed energy injection implementation using comparators.

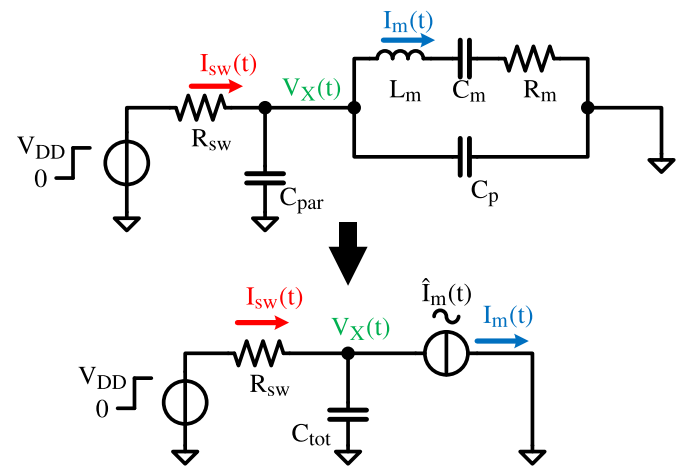

Fig. 6. Model of the start-up circuit during one switch period

\section{B. Switch resistance}

The current sensing sensitivity is critical at the beginning of start-up, where $\hat{I}_{m}(t)$ is smallest. A high switch resistance $R_{s w}$ is desired to maximize this sensitivity, resulting in a voltage drop $I_{m}(t) \cdot R_{s w}$. However, a non-zero switch impedance has two side effects. Firstly, the voltage over the crystal does not immediately settle to $+V_{D D}$ or $-V_{D D}$ due to the RC-time constant of $C_{p}$ being charged through $R_{s w}$. Secondly, part of the current $I_{m}(t)$ flows through $C_{P}$ and part of it through the switch, such that there is a phase shift between $I_{m}$ and $I_{s w}$.

To analyze these effects during a single switch cycle, the circuit can be modelled as shown in Fig. 6. The motional branch has a high Q-factor, such that it can be approximated as a sinusoidal current source with amplitude $\hat{I}_{m}(t)$, which increases with each switching cycle. The model includes a parasitic capacitance $C_{\text {par }}$, consisting of parasitics like comparator input capacitance, bondpad capacitance and PCB trace capacitance. The current through $R_{s w}$ can be separated in the individual contributions due to charging of $C_{t o t}=C_{p}+C_{p a r}$ and the motional current $I_{m}(t)$.

\section{1) Charging current}

The current through $R_{s w}$ due to charging $C_{p}$ and $C_{p a r}$ can be calculated as:

$$
I_{s w, \text { charge }}(t)=\frac{V_{D D}-V_{X}(0)}{R_{s w}} e^{-\frac{t}{R_{S w} C_{t o t}}}
$$

In this expression $C_{\text {tot }}=C_{p}+C_{\text {par }}$, and $V_{X}(0)$ is the initial voltage at the crystal terminal. The voltage over $C_{\text {par }}$ starts at $0 \mathrm{~V}$, while $C_{p}$ is initialized to $-V_{D D}$ as a result of charging to $V_{D D}$ in the previous switch state. After switching, $C_{p}$ and $C_{p a r}$ share charge, such that the initial voltage $V_{X}(0)$ can be calculated as:

$$
V_{X}(0)=-V_{d d} \frac{C_{p}}{C_{p}+C_{p a r}}
$$

\section{2) Motional branch current}

$R_{s w}$ and $C_{t o t}$ form an RC-filter, which affects the phase and amplitude of the current $I_{s w}$ with respect to $I_{m}$. The current through $R_{s w}$ due to the motional current $I_{m}$ can be calculated as:

$$
I_{s w, I_{m}}(t)=A \hat{I}_{m}(t) \sin (\omega t-\varphi)
$$

Where:

$$
\begin{gathered}
\varphi=\tan ^{-1} \frac{1}{\omega R_{s w} C_{t o t}} \\
A=\frac{1}{\sqrt{1+\left(\omega R_{s w} C_{t o t}\right)^{2}}}
\end{gathered}
$$

3) Total switch current

By superposition, equations (1) and (3) can be added to yield the total switch current:

$$
\begin{aligned}
& I_{s w}(t)=A \hat{I}_{m}(t) \sin (\omega t-\varphi) \\
& +\frac{V_{D D}-V_{X}(0)}{R_{s w}} e^{-\frac{t}{R_{s w} C_{t o t}}}
\end{aligned}
$$

Fig. 7 shows the individual contributions, as well as the total switch current $I_{s w}(t)$, over an oscillation period $T$.

Ideally, we would like the comparator to detect the zero crossing of $I_{m}(t)$, occurring at $t=\frac{T}{2}$. The actual decision is taken when $I_{S w}=0$, which is later than $t=\frac{T}{2}$ and depending on the switch resistance, as illustrated in Fig. 8. Furthermore, delay from, for example, the comparator or D flip-flop, increases the time between the ideal switching time and the actual switch time. The latest point in time at which the injection waveform may switch is 90 degrees $\left(\frac{T}{4}\right)$ out of phase with $I_{m}$, as otherwise the oscillation would be damped instead of amplified. For a comparator delay $T_{D, \text { comp }}$, this means that that $I_{S w}\left(\frac{3}{4} T-\right.$ $\left.T_{D, \text { comp }}\right)<0$, as illustrated in Fig. 8. Substitution in (4) yields:

$$
\begin{aligned}
& \frac{1}{\sqrt{1+\left(\omega R_{s w} C_{t o t}\right)^{2}}} \hat{I}_{m}(\mathrm{t}) \sin \left(\frac{3}{2} \pi\right. \\
&\left.-\tan ^{-1} \frac{1}{\omega R_{S w} C_{t o t}}\right) \\
&+\frac{V_{D D}}{R_{S w}} e^{-\frac{\frac{3}{4} T-T_{D}, c o m p}{R_{S w} C_{t o t}}}<0
\end{aligned}
$$

This equation can be solved (numerically) for $R$ to find the maximum switch resistance $R_{\max }$. 

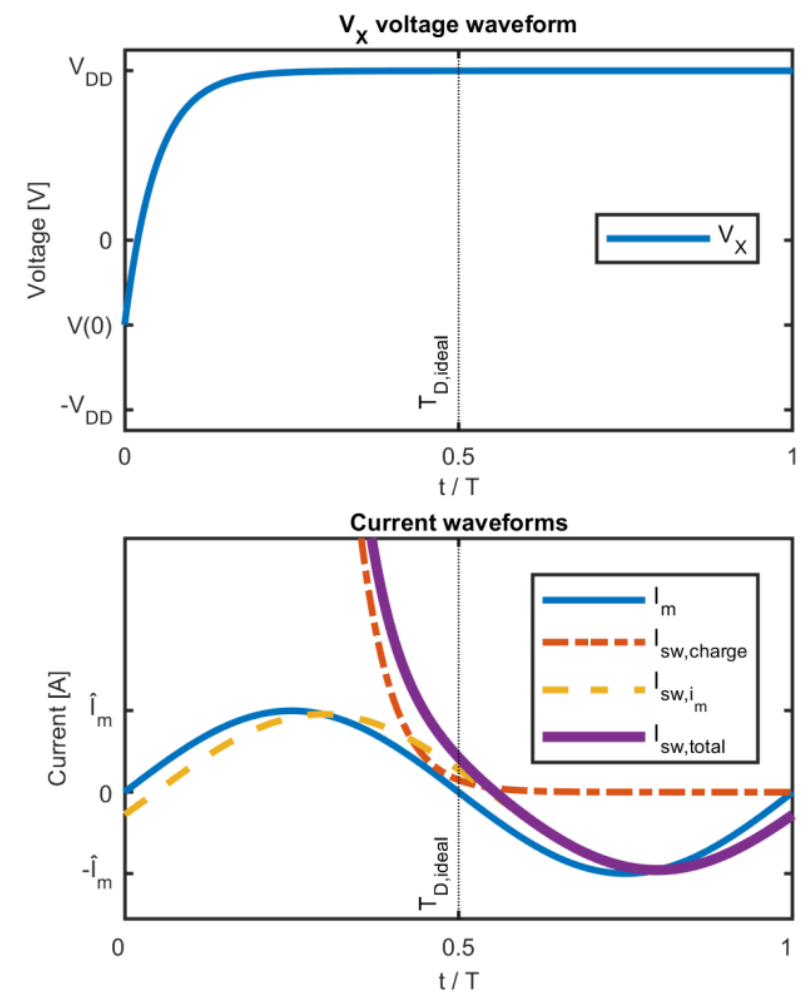

Fig. 7. Modelled crystal voltage and switch current for a single switching event and (large) non-zero switch resistance. In actual operation, the circuit would switch again just after $\mathrm{t}=\mathrm{T} / 2$.

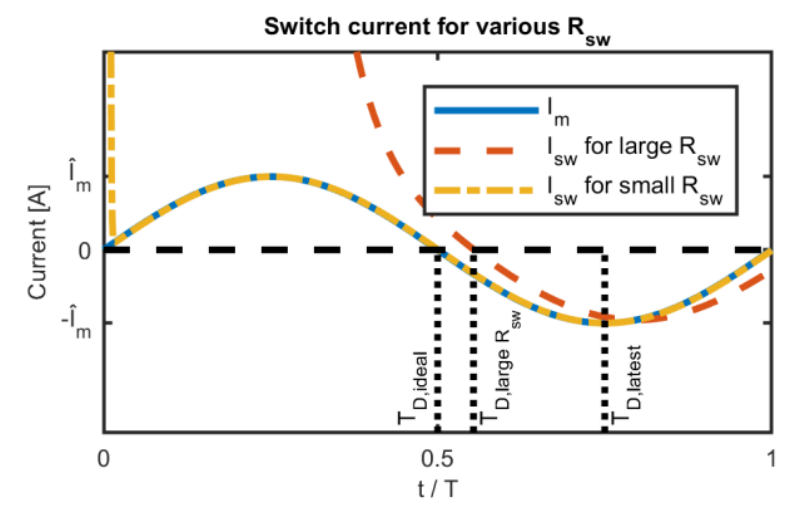

Fig. 8. Switch current for various switch resistances.

Note that $T_{D, \text { comp }}$ is in practice amplitude dependent, and $\hat{I}_{m}(\mathrm{t})$ is time dependent. However, the first cycle is most critical since the motional current is at its smallest. Each cycle, the amplitude $\hat{I}_{m}$ grows and the specifications on comparator and switch resistance become more relaxed. To maximize the initial current, a 'single kick' is given to the crystal by applying a voltage step equal to the supply. The initial current amplitude after this 'single kick' can be found by calculating the step response of an LC circuit to a step with amplitude $V_{D D}$, resulting in $\hat{I}_{m}(0)=V_{D D} \sqrt{\frac{C_{m}}{L_{m}}}$, which is in the range of $150 \mathrm{nA}-2 \mu \mathrm{A}$ for typical crystals ranging between $16-50 \mathrm{MHz}$. Substituting in the equation for $R_{\max }$ and assuming that the comparator delay is negligible results in a maximum switch resistance that is typically in the order of $1 \mathrm{k} \Omega$, depending on the crystal and the parasitics.

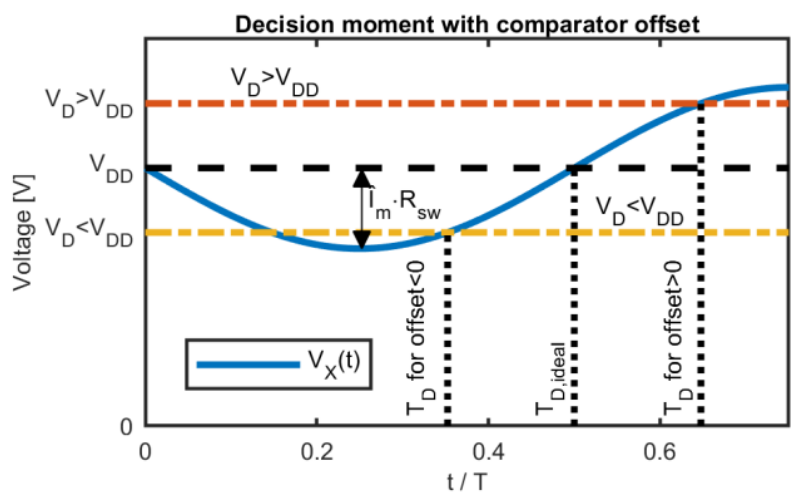

Fig. 9. Decision moment variation over comparator offset, where $V_{D}$ is the decision voltage.

\section{Comparator specifications}

Comparator offset results in decisions taken early or late, as illustrated in Fig. 9. If the offset is positive, the comparator decision is slightly late, while for a negative offset, the decision is taken slightly early. As discussed in section 0 , the decision is delayed with respect to the ideal decision moment due to charging of (parasitic) capacitances and comparator delay. Too much delay slows down the start-up process or can even dampen the oscillation. Therefore, in the circuit implementation we make sure that the decision threshold is always below $V_{D D}$.

With this decision threshold always below the supply, comparator offset will cause a current-referred offset $\frac{\left|V_{\text {offset }}\right|}{R_{S w}}$, causing early comparator decision. The earliest allowable decision moment is at $t=\frac{T}{4}$. Hence,

$$
I_{S W}\left(\frac{T}{4}\right)<\frac{\left|V_{\text {offset }}\right|}{R_{S w}}
$$

Using equation (4), this equation can be solved (numerically) for the maximum allowable offset for a given switch resistance. Fig. 10 shows the allowable offset for different values of comparator delay, for a $50 \mathrm{MHz}$ crystal with $L_{m}=1.18 \mathrm{mH}$ and $C_{\text {tot }}=7 p F$. Furthermore, the allowable switch resistance range is indicated, as calculated from equation (5), showing the design space of offset versus switch resistance that permits the oscillation to start at a frequency that will inject energy into the crystal.

Note that the current-referred offset may be larger than $\hat{I}_{m}(0)$, but start-up is still achieved as long as the decision moment is after $\frac{T}{4}$. In this case, the circuit can be regarded as a relaxation oscillator. This behavior, due to the RC-charging of $C_{p}$, is taken into account in the previous analysis. This means that, as long as the requirements set on offset and switch resistance are fulfilled, energy is injected into the crystal in each cycle such that $\hat{I}_{m}(\mathrm{t})$ grows. 


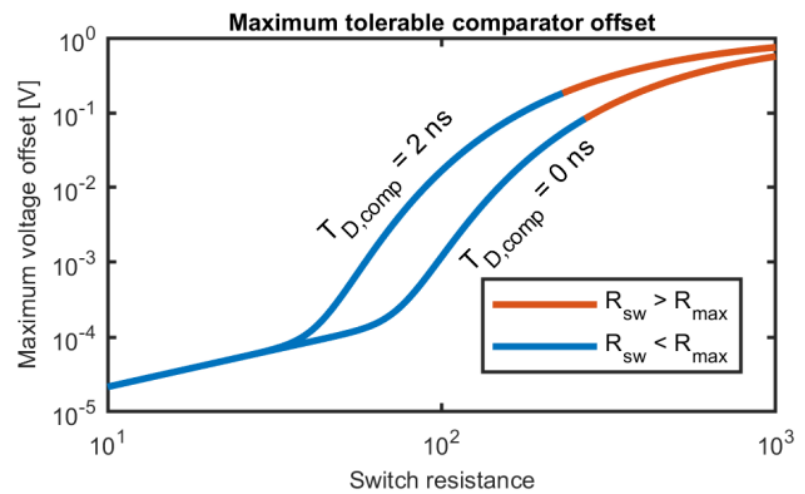

Fig. 10. Maximum tolerable offset against switch resistance.

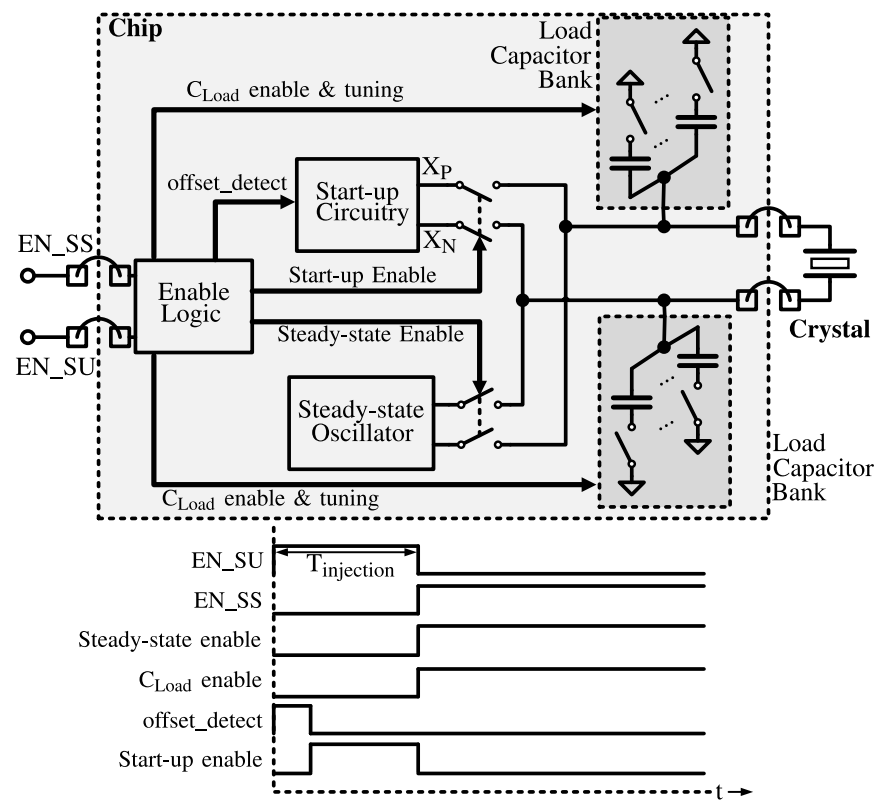

Fig. 11. Circuit block diagram and timing diagram

\section{CIRCUIT IMPLEMENTATION}

A block diagram of the implemented circuit is shown in Fig. 11. The enable logic block enables the appropriate circuit blocks for start-up or steady-state. During start-up, the offset detection is briefly enabled, after which the start-up circuitry starts injecting energy into the crystal. The $15 \mathrm{pF}$ load capacitor bank consist of $1 \mathrm{pF}$ unit elements to allow various load capacitances, and is disconnected during start-up to minimize $C V^{2}$ losses.

After a pre-determined (externally controlled) start-up time, the start-up control block disables the start-up circuitry. The steadystate oscillator and as well as the load capacitor bank are then enabled by closing the appropriate switches.

\section{A. Start-up circuit}

Fig. 12 shows the block diagram of the start-up circuitry. Since only one comparator is active at any instant in time, a single comparator is used, with a switch matrix that is controlled by the Switch Control Logic, to connect the appropriate comparator inputs. The Switch Control Logic block consists of static combinational logic. When the start-up circuit is enabled, the D flip-flop toggles every time the comparator detects a zerocrossing. This in turn toggles the H-bridge switches, as well as the comparator inputs, repeating the process until the start-up circuitry is disabled.

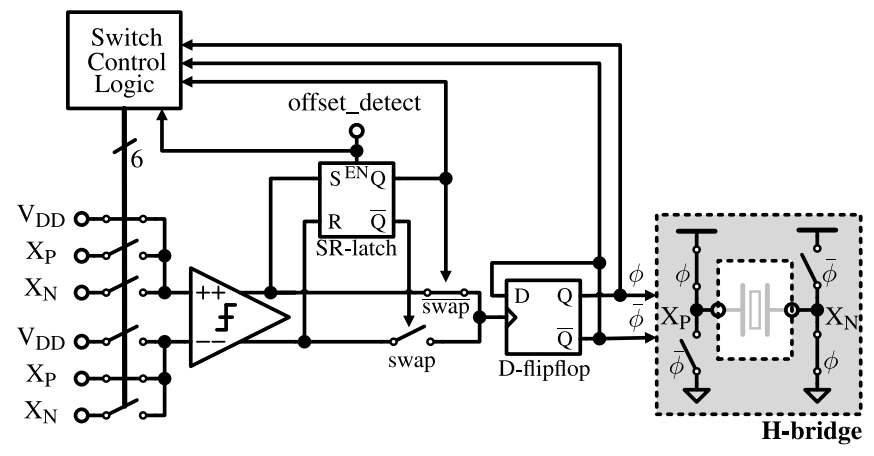

Fig. 12. Start-up circuit block diagram

During the first $80 \mathrm{~ns}$ of each start-up cycle, the comparator offset sign detection is enabled by the enable logic. During this phase, both comparator inputs are connected to $V_{D D}$. The comparator output, which indicates the sign of the offset, is stored in an SR-latch. This serves as an input for the switch control logic, which swaps the comparator inputs and output when necessary to make sure the decision threshold is always below $V_{D D}$.

The comparator is implemented as a continuous time (limiting) amplifier, as shown in Fig. 13. The first differential pair is large to minimize offset, and is connected to a symmetric active load. A second differential stage increases the gain and converts to a single-ended output, which is amplified by cascaded inverters generating rail-to-rail outputs.

The schematic of the H-bridge is shown in Fig. 14. A lowimpedance path to ground is provided by large NMOS switches. The PMOS switches to the supply act as measurement resistors. Their impedance is binary scalable over a range of approximately $40 \Omega$ to $1.3 \mathrm{k} \Omega$ to accommodate various crystals having different requirements on settling time and detection sensitivity. Self-quenching NMOS switches are connected in parallel to the PMOS switches to quickly pull-up the respective crystal nodes to $V_{D D}-V_{T H, N}$ after a switch event. In our current implementation, this allows a reduction in settling time by approximately one third, while retaining the PMOS switch resistance for current detection sensitivity. $55 \mathrm{pF}$ of decoupling capacitance is integrated on-chip. Simulations show that any ringing due to switching of the $\mathrm{H}$-bridge has damped before the next zero-crossing of $I_{m}(t)$.

\section{B. Steady-state oscillator}

To demonstrate the transition from start-up to steady-state, a self-biased NMOS oscillator is integrated, as shown in in Fig. 15. There is no amplitude control loop for simplicity. The bias current, however, is externally tunable to accommodate various crystals, as well as enabling manual amplitude control. Binary switches allow coarse tuning, while analog fine-tuning is possible through an external pin. Self-quenched NMOS transistors, triggered by a delay-line as one-shot, pull the load capacitor voltages to $\mathrm{V}_{\mathrm{dd}}-\mathrm{V}_{\text {th }}$ to reduce the settling time of the steady-state oscillator during the transition from start-up to steady-state. The $C V^{2}$ energy consumption associated with charging the load capacitors is negligible. 


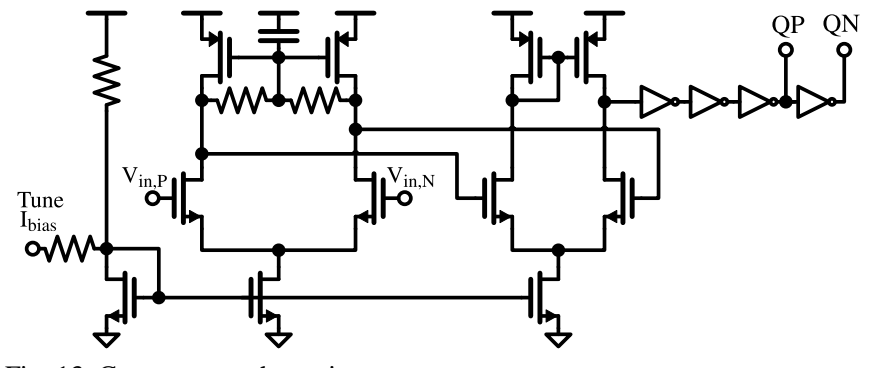

Fig. 13. Comparator schematic

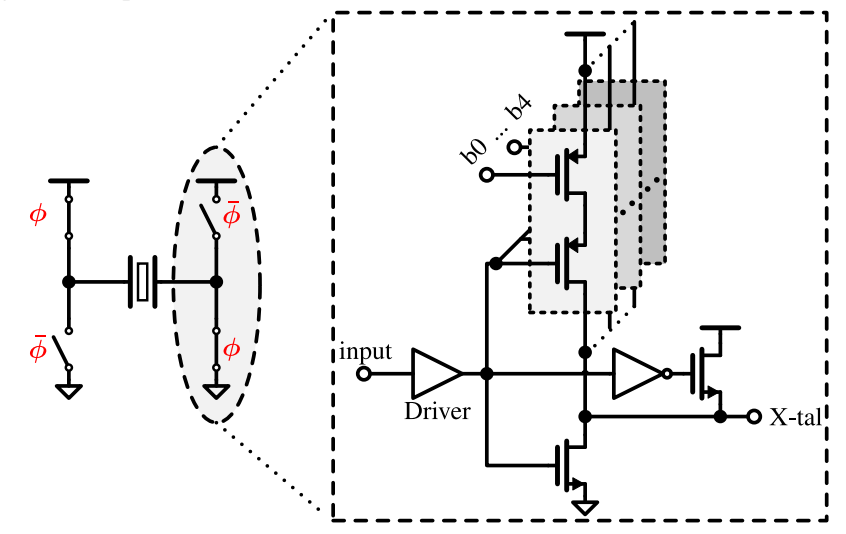

Fig. 14. H-bridge schematic

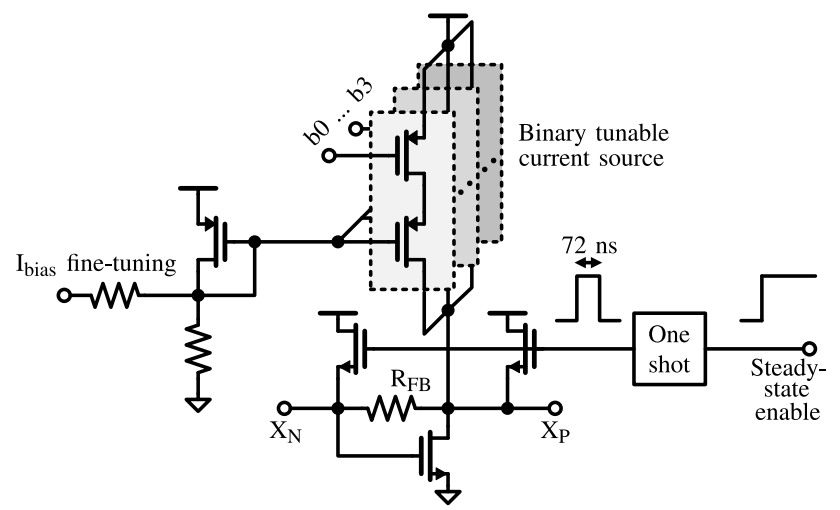

Fig. 15. Steady-state oscillator schematic

\section{SimULATION RESULTS}

The proposed circuit is implemented in a $22 \mathrm{~nm}$ FD-SOI technology with $0.8 \mathrm{~V}$ supply voltage. Fig. 16 shows waveforms for full-chip simulations with a $50 \mathrm{MHz}$ crystal. At $t=0$, the start-up circuit is activated, linearly increasing $\hat{I}_{m}$ after a brief offset sign detection phase. Although the initial injection frequency error is large, energy is injected in the crystal during the first few cycles, causing a linear growth of $I_{m}(t)$. If the injection frequency were to be constant, $I_{m}(t)$ would quickly saturate because the injection phase drifts away from the crystal phase. However, using the proposed technique, the injection phase aligns itself with the crystal oscillation as $\hat{I}_{m}(\mathrm{t})$ grows. The injection frequency therefore converges to the crystal (series) frequency, allowing $I_{m}(t)$ to keep growing (approximately) linearly. At $t=3.4 \mu \mathrm{s}$, the start-up circuit is disabled and the steady-state oscillator and load capacitors are enabled. The resonance frequency immediately switches to the parallel resonance frequency as evident from the frequency of
$I_{m}(t)$, while the frequency of the output voltage requires some settling time (approximately 6-7 $\mu \mathrm{s}$ ). The simulated time required for the output frequency to settle within $20 \mathrm{ppm}$ is 6.9 $\mu \mathrm{s}$, mainly due to DC settling of the steady-state oscillator. The steady-state oscillator has a differential swing of $320 \mathrm{mVpp}$. The switches that (dis)connect the crystal to the steady-state oscillator and load capacitors have negligible effect on phase noise performance.

Table I lists the simulated start-up energy breakdown for a $50 \mathrm{MHz}$ crystal, as used in [8]. Most of the energy is consumed by the H-bridge, consisting predominantly of $C V^{2}$ losses from (dis)charging its capacitive load $C_{t o t}$, consisting of both crystal $C_{p}$ and circuit parasitics.

\section{A. PVT variations \& mismatch}

As discussed in section II.C, comparator offset is an important factor in start-up time. The simulated comparator $1-\sigma$ offset is $0.8 \mathrm{mV}$. Fig. 17 shows Monte-Carlo simulation results for local mismatch in the typical process corner, showing the spread in start-up time and energy after injecting energy for $3.4 \mu \mathrm{s}$ to a $50 \mathrm{MHz}$ crystal, without any calibration or tuning.

As the steady-state oscillator in the prototype is unregulated, the steady-state amplitude varies greatly over process corners. However, in a practical implementation, the steady-state oscillator would be compensated to have a constant swing over PVT variations. To achieve this swing in the shortest possible time, the injection time could be corrected as to yield the nominal steady-state current. Since $\hat{I}_{m}$ is approximately a linear function of $T_{i n j}$, this could be achieved with a single trim. The additional start-up time due to variation in $T_{i n j}$ is listed in Table II. Simulations over extreme process corners confirm that startup is achieved over process variations, as shown in Table II. $\hat{I}_{m}\left(T_{i n j}\right)$ is within $+/-25 \%$ of its nominal value after a fixed injection time of $3.4 \mu \mathrm{s}$, without any tuning or calibration. The third and fourth column lists the required adjustment in $T_{i n j}$ to result in the same steady-state swing and the resulting settling time, respectively. Note that the variation in start-up time is mostly due to DC settling of the steady-state oscillator.

Simulations show minimal variation over circuit temperature, with $\hat{I}_{m}\left(T_{i n j}\right)$ varying less than $3 \%$ over $-40-+85^{\circ} \mathrm{C}$. The settling time, however, varies between 6 and $9.6 \mu$ s due to the variation in steady-state oscillator settling. Simulations over supply voltages between $750-850 \mathrm{mV}$ show a variation in $\hat{I}_{m}\left(T_{i n j}\right)$ ranging from $763-1041 \mu \mathrm{A}$, and start-up times between

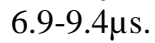

Variation of the crystal $L_{m}$, just like other injection techniques, has a direct influence the growth of $I_{m}(t)$ since its slope varies with $\frac{A}{2 L_{m}}$. Simulations show successful start-up for $C_{p}$ varying over $\pm 50 \%$, as well as robustness over crystal quality factor, with only $3 \%$ variation in $I_{m}\left(T_{i n j}\right)$ for a 5 times lower quality factor. These large variations in crystal parameters are unlikely to be encountered in practice. 

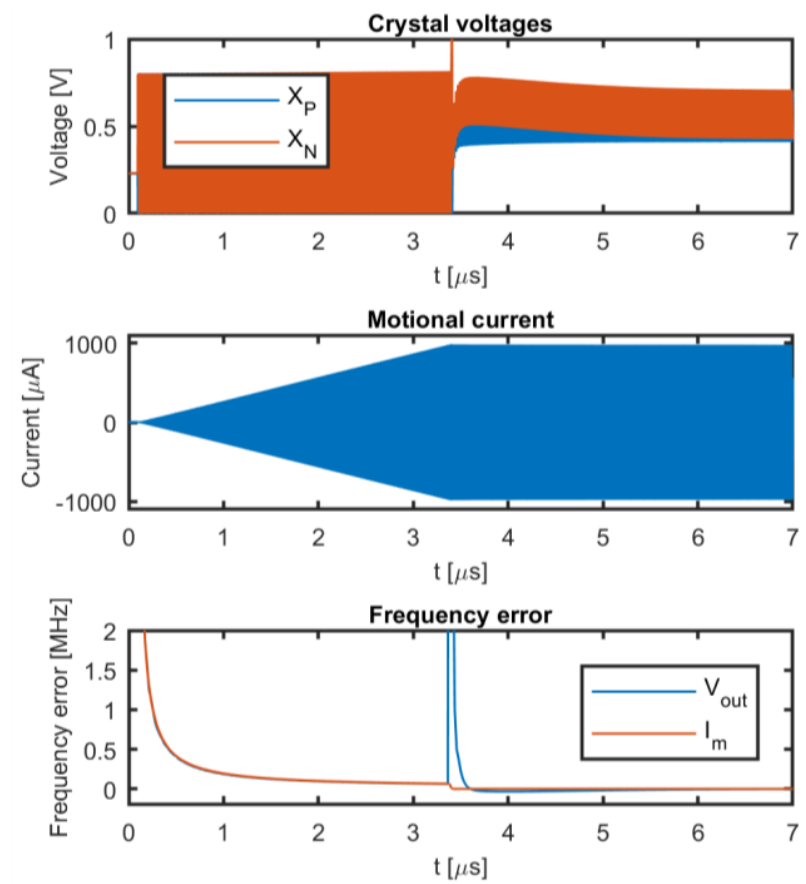

Fig. 16. Simulated waveforms for a $50 \mathrm{MHz}$ crystal.

TABLE I

SIMULATED START-UP ENERGY BREAKDOWN

\begin{tabular}{|l|c|c|}
\cline { 2 - 3 } \multicolumn{1}{c|}{} & Energy $(\mathbf{n J})$ & \% of total energy \\
\hline Frequency $[\mathbf{M H z}]$ & \multicolumn{2}{|c|}{$\mathbf{5 0}$} \\
\hline H-bridge & 2.32 & $73 \%$ \\
\hline Comparator & 0.49 & $15 \%$ \\
\hline Logic etc. & 0.03 & $1 \%$ \\
\hline Steady-state oscillator settling & 0.33 & $10 \%$ \\
\hline Total start-up energy & $\mathbf{3 . 1 9}$ & $100 \%$ \\
\hline
\end{tabular}
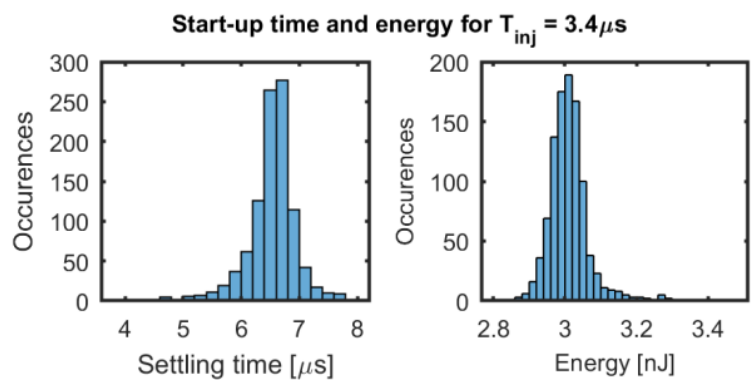

Fig. 17. Monte Carlo simulation results for a $50 \mathrm{MHz}$ crystal over 1016 points for an injection time of $3.4 \mu \mathrm{s}$.

TABLE II

SIMULATED VARIATION OVER EXTREME PROCESS CORNERS AT $20^{\circ}$

\begin{tabular}{|l|c|c|c|c|}
\hline Corner & $\begin{array}{c}\hat{\boldsymbol{I}}_{\boldsymbol{m}}\left(\boldsymbol{T}_{\boldsymbol{i n j}}\right) \\
(\boldsymbol{\mu A})\end{array}$ & $\begin{array}{c}\mathbf{T}_{\text {start }}(\boldsymbol{\mu \mathbf { s }}) \\
(\mathbf{u n t r i m m e d})\end{array}$ & $\boldsymbol{\Delta}_{\mathbf{i n j}}(\boldsymbol{\mu \mathbf { s } )})$ & $\begin{array}{c}\mathbf{T}_{\text {start }}(\boldsymbol{\mu \mathbf { s } )} \\
(\text { trimmed) }\end{array}$ \\
\hline Nominal & 908 & 6.9 & 0 & 6.9 \\
\hline SS & 679 & 12.0 & +1.07 & 10.2 \\
\hline FF & 1048 & 6.3 & -0.46 & 4.6 \\
\hline FS & 916 & 7.3 & -0.03 & 7.3 \\
\hline SF & 899 & 9 & 0.03 & 8.8 \\
\hline
\end{tabular}

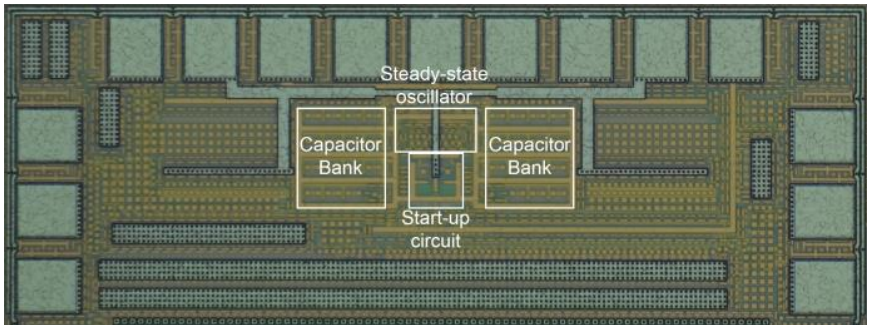

Fig. 18. Chip photo

\section{MEASUREMENT RESULTS AND DISCUSSION}

The proposed circuit was fabricated in Global Foundries' $22 \mathrm{~nm}$ FD-SOI CMOS process. A photo of the fabricated test-chip is shown in Fig. 18. The area breakdown is listed in Table III. The output voltages are buffered by off-the-shelf amplifiers (LTC6268) in unity-gain configuration. Fig. 19 shows the conventional start-up sequence (without the proposed start-up technique) for a $5 \times 3.2 \mathrm{~mm} 50 \mathrm{MHz}$ crystal from the Abracon ABM3 series. The start-up time is more than $16 \mathrm{~ms}$, for an energy consumption exceeding $0.8 \mu \mathrm{J}$. This long time is the result of the oscillator bias current being fixed for the final steady-state swing. The start-up would have been faster with an amplitude control loop.

The optimum injection time depends on the crystal frequency, as well as the desired output swing, which depends on $\hat{I}_{m}$ and motional inductance, as well as the load capacitance. The injection time is controlled by an external microcontroller, but could easily be integrated on-chip by e.g. counting comparator decisions. The optimum injection time is manually (iteratively) determined once to reach the desired steady-state swing, as in the prototype it is not possible to detect if the steady-state amplitude has been reached during injection. The switch resistance is also determined manually, depending on the crystal's motional inductance and parallel capacitance. The injection time and switch resistance are kept constant in the measurements over voltage and temperature variations. Fig. 20 shows the start-up transient with the proposed energy injection technique. After the injection time of $3.4 \mu$ s, the steady-state oscillator quickly settles to its steady-state amplitude, with a total start-up time of $6 \mu \mathrm{s}$.

Fig. 21 shows the measured frequency error during start-up, as measured using a wide $(25 \mathrm{MHz}) \mathrm{IF}$ bandwidth. The injection frequency settles towards the crystal series resonance frequency during energy injection, and quickly settles towards the parallel resonance frequency after switching to steady-state, causing a frequency step after $T_{i n j}$. Although the initial injection frequency error is large, this happens during such a short time interval that the growth of $I_{m}$ is not hampered. 
TABLE III

AREA BREAKDOWN

\begin{tabular}{|l|c|c|}
\multicolumn{1}{c|}{} & \multicolumn{1}{c|}{ AREA BREAKDOWN } \\
\cline { 2 - 3 } \multicolumn{1}{c|}{} & Area $\left(\mathbf{m m}^{2}\right)$ & Fraction of total area \\
\hline Start-up circuitry & 0.0025 & $12.6 \%$ \\
\hline Steady-state oscillator & 0.0033 & $16.6 \%$ \\
\hline Load capacitor banks & 0.0140 & $70.7 \%$ \\
\hline Total & 0.0198 & $100 \%$ \\
\hline
\end{tabular}

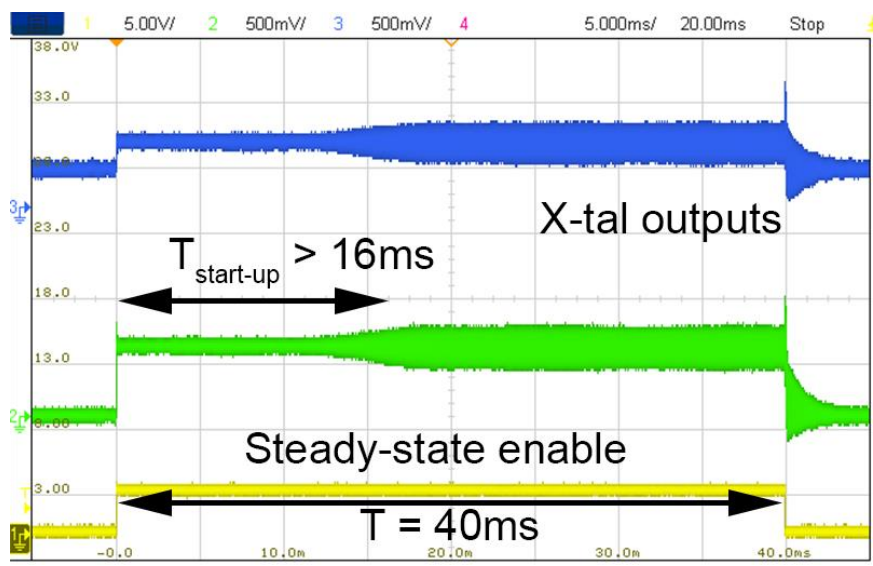

Fig. 19. Measured output voltages for a $50 \mathrm{MHz}$ crystal in a $5 \times 3.2 \mathrm{~mm}$ package, without energy injection.

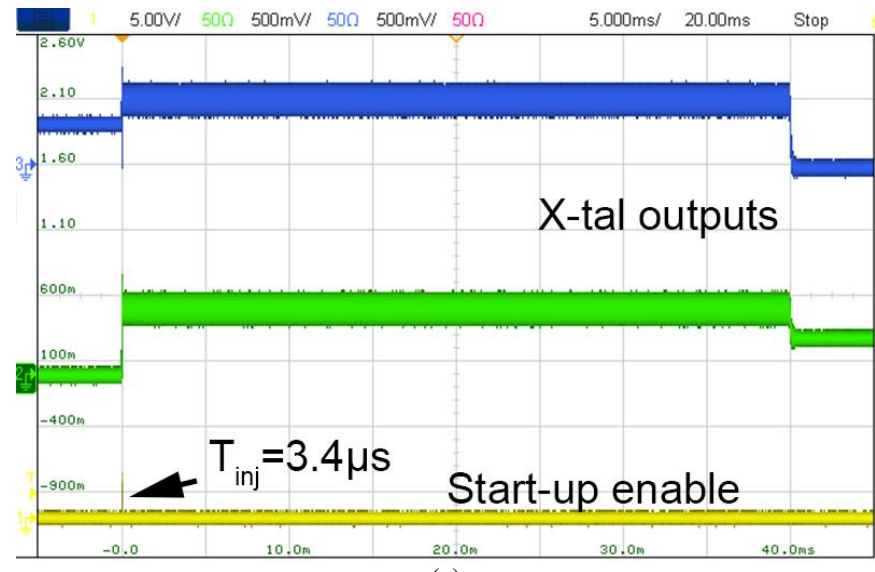

(a)

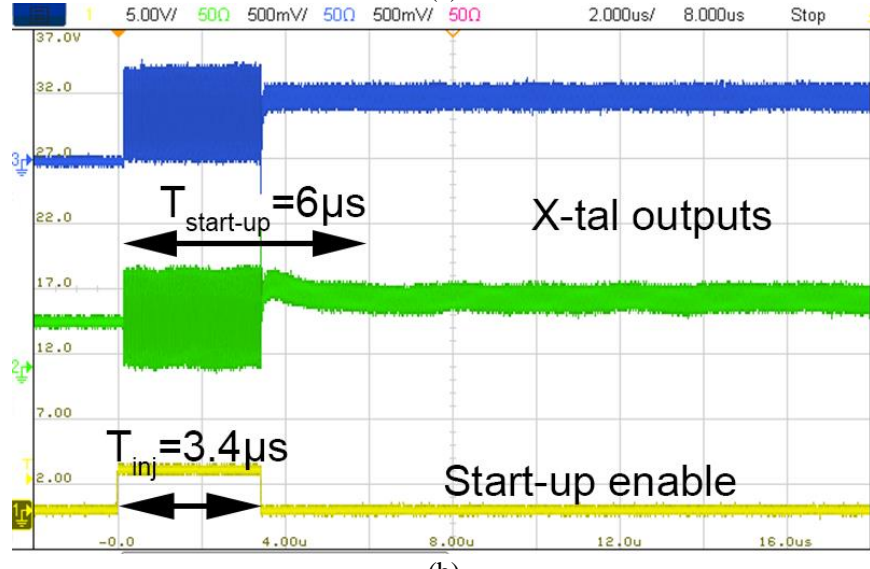

(b)

Fig. 20. (a) Measured output voltages for a $50 \mathrm{MHz}$ crystal in a $5 \times 3.2 \mathrm{~mm}$ package, with energy injection, for $\mathrm{T}_{\mathrm{inj}}=3.4 \mu \mathrm{s}$, at $\mathrm{T}=20^{\circ}$. (b) Zoomed in.

As with any energy injection technique, driving the crystal not only excites the crystal fundamental tone, but other spurious tones as well. These become visible as slight frequency deviations after energy injection, until these spurs have damped after 1-2 ms. To show the frequency settling of the fundamental, the center frequency and IF bandwidth in measurement can be chosen such that the spurious tones fall out of band, assuming that a PLL would normally filter out these spurs. Fig. 22 shows the frequency settling measurement, showing that the frequency has settled within 20 ppm after only $6 \mu \mathrm{s}$.

The settling time after $T_{i n j}$ is mainly due to DC settling of the steady-state circuit, and could be improved by reducing $R_{f b}$ (now $190 \mathrm{k} \Omega$ ) in the steady-state oscillator, at the cost of increased power consumption. This is confirmed by simulation, showing that halving $R_{f b}$ results in $45 \%$ reduction of the settling time. The measured start-up energy is $3.7 \mathrm{~nJ}$, more than 2 orders of magnitude lower than without the proposed injection technique.

Note that for measurement flexibility, the injection duration is externally controlled in the proposed prototype. However, an (initially inaccurate) clock signal is immediately available at the comparator output, which could be used to self-time the startup circuit, e.g. by counting the number of cycles. An additional oscillator to generate this timing is therefore not necessary. Additionally, this clock could be used for e.g. coarse settling of a PLL or clocking digital circuitry.

Fig. 23 and Fig. 24 show the measured start-up time and energy over temperature and voltage, respectively. For both measurements, the injection time is kept constant. The steadystate oscillator bias current is manually adjusted to keep the amplitude constant.

Fig. 25 shows the measured and simulated amplitude just after disabling the start-up circuitry, as a function of $T_{i n j}$. The measured amplitude for long injection times is significantly lower than those of the extracted simulations. Inclusion of additional board parasitics and comparator offset in the simulation did not improve the match, leaving the exact reason of the deviation unknown. Fig. 26 shows the measured start-up time over switch resistance variation.

The measured phase noise is $-123 \mathrm{dBc} / \mathrm{Hz}$ at $1 \mathrm{kHz}$ offset. The phase noise can be lowered by increasing the injection time and steady-state bias current, increasing the output swing at the expense of increased (start-up) energy consumption.

Table IV lists the measured performance, for both a $24 \mathrm{MHZ}$ and a $50 \mathrm{MHz}$ crystal, and compares it to the state-of-the-art. A startup time and startup energy comparison is also graphically displayed in Fig. 27. Compared to the work with the lowest $E_{\text {start }}$ in literature, which uses energy injection, start-up time is longer due to a lower injection amplitude caused by a lower supply voltage, as well as comparator delay. However, the energy consumption, using identical crystal part numbers, is 2.6 times lower. 


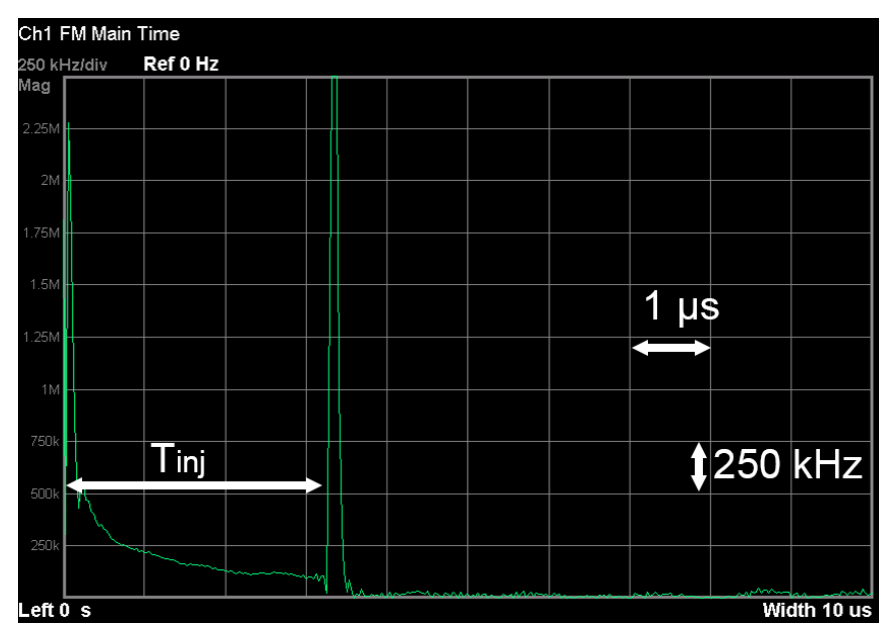

Fig. 21. Measured frequency error at $20^{\circ} \mathrm{C}$

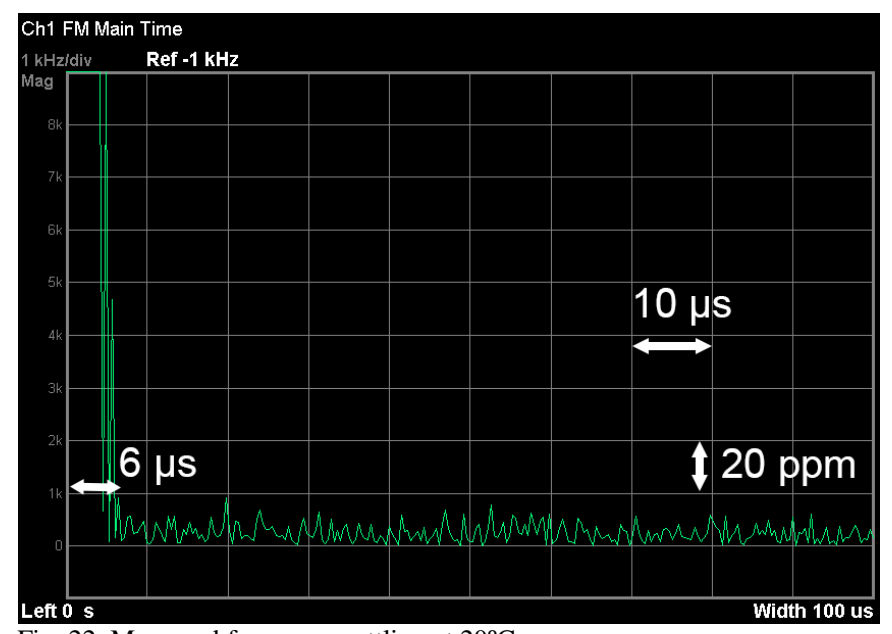

Fig. 22. Measured frequency settling at $20^{\circ} \mathrm{C}$
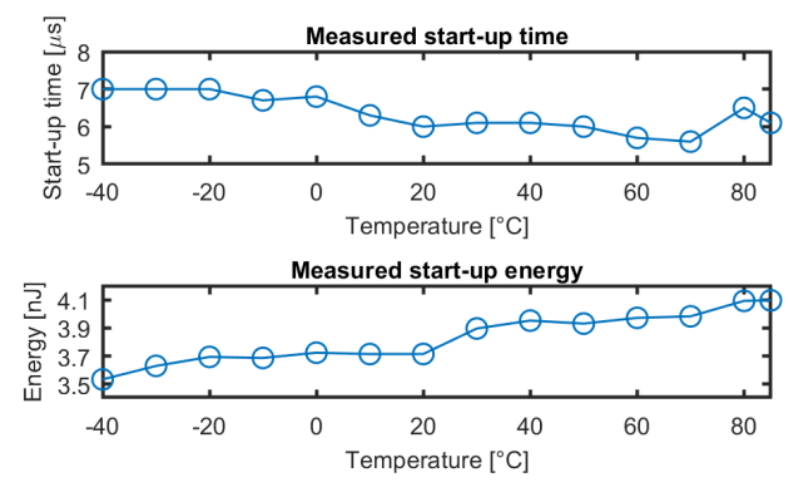

Fig. 23. Measured start-up time and energy over temperature for $\mathrm{T}_{\mathrm{inj}}=3.4 \mu \mathrm{s}$.
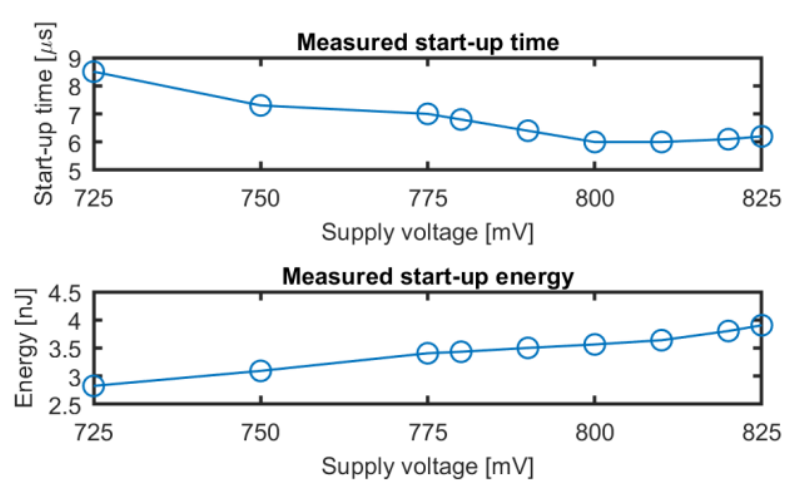

Fig. 24. Measured start-up time and energy over supply voltage for $T_{\text {inj }}=3.4 \mu \mathrm{s}$.

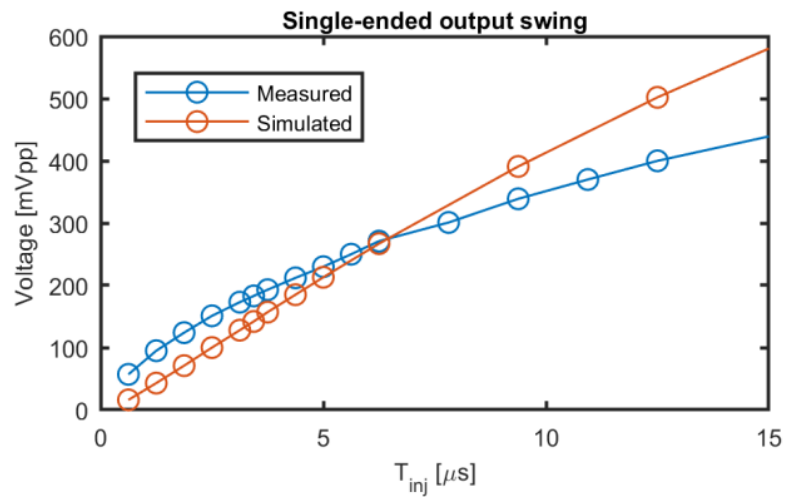

Fig. 25. Measured and simulated output voltage swing as function of $T_{i n j}$

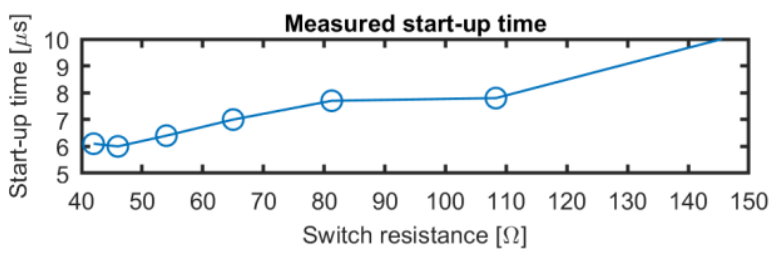

Fig. 26. Measured start-up time over switch resistance variation for $\mathrm{T}_{\text {inj }}=3.4 \mu \mathrm{s}$

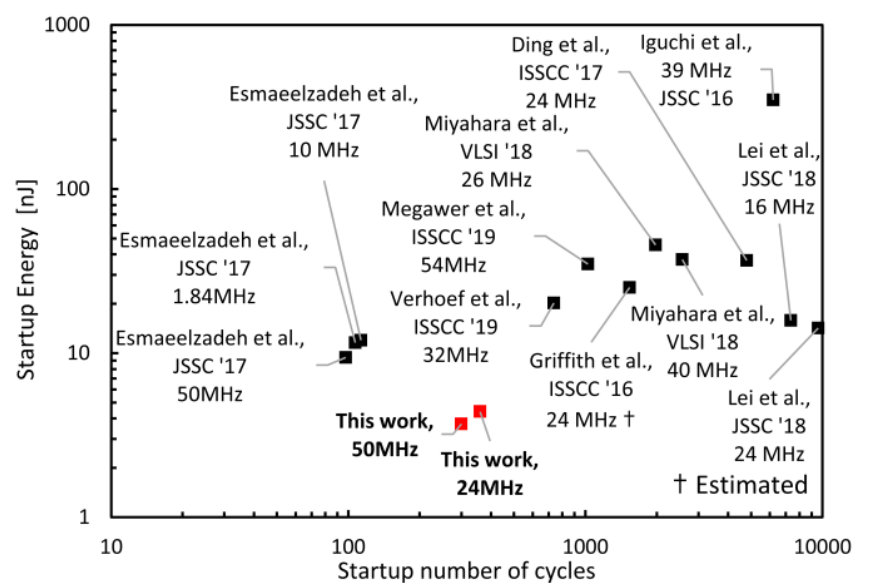

Fig. 27. Start-up energy versus start-up time of the current state-of-the-art crystal oscillators. Estimated value obtained by multiplying start-up time with steady-state power. 
TABLE IV

COMPARISON WITH PRIOR ART

\begin{tabular}{|c|c|c|c|c|c|c|c|c|c|c|}
\hline & & & MNDON n & П & & & & & & \\
\hline & $\begin{array}{c}\text { JSSC'16 } \\
{[10]}\end{array}$ & $\begin{array}{c}\text { TCAS-I'18 } \\
{[16]}\end{array}$ & $\begin{array}{c}\text { VLSI'18 } \\
{[17]}\end{array}$ & $\begin{array}{c}\text { JSSC'18 } \\
{[13]} \\
\end{array}$ & \begin{tabular}{|c|} 
ISSCC'16 \\
{$[9]$} \\
\end{tabular} & $\begin{array}{c}\text { ISSCC'19 } \\
{[14]}\end{array}$ & $\begin{array}{c}\text { ISSCC'19 } \\
{[15]}\end{array}$ & $\begin{array}{c}\text { JSSC'17 } \\
{[8]}\end{array}$ & \multicolumn{2}{|c|}{ This work } \\
\hline CMOS process (nm) & 180 & 90 & 65 & 65 & 65 & 65 & 55 & 65 & \multicolumn{2}{|c|}{$22 \mathrm{FD}-\mathrm{SO}$} \\
\hline Supply voltage (V) & 1.5 & 1.0 & 1.2 & 0.35 & 1.68 & 1.0 & 1.2 & 1 & \multicolumn{2}{|c|}{0.8} \\
\hline Active area $\left(\mathrm{mm}^{2}\right)$ & 0.12 & 0.07 & 0.005 & 0.02 & 0.08 & 0.07 & 0.05 & 0.09 & \multicolumn{2}{|c|}{0.02} \\
\hline Frequency (MHz) & 39.25 & 24 & 40 & 24 & 24 & 54 & 32 & 50 & 24 & 50 \\
\hline Load capacitance (pF) & 8 & 10 & 9 & 6 & 6 & 6 & 6 & 9 & 6 & 7 \\
\hline Steady-state amplitude (Vpp) & 1.5 & N/A & N/A & 0.3 & N/A & 0.7 & 0.75 & 0.25 & \multicolumn{2}{|c|}{0.32} \\
\hline $\begin{array}{l}\text { Steady-state power } \\
\text { consumption }(\mu \mathrm{W})\end{array}$ & 181 & 95 & 141 & 32 & 393 & 198 & N/A & 195 & 10 & 51 \\
\hline Start-up time $(\mu \mathrm{s})$ & 158 & 200 & 64 & 400 & 64 & 19 & 23 & 1.95 & 15 & 6 \\
\hline Temperature range $\left({ }^{\circ} \mathrm{C}\right)$ & $-30-125$ & $-40-90$ & $-20-85$ & $-40-90$ & $-40-90$ & $-40-85$ & $-40-140$ & $-40-85$ & \multicolumn{2}{|c|}{$-40-85$} \\
\hline $\begin{array}{c}\text { Start-up time variation over } \\
\text { temperature }\left({ }^{\circ} \mathrm{C}\right)\end{array}$ & $\pm 7 \%$ & $28 \%$ & $\pm 10 \%$ & $8 \%$ & $\pm 35 \%$ & $\pm 1 \%$ & $\pm 11 \%$ & $10 \%$ & N/A & $23 \%$ \\
\hline Start-up time (cycles) & 6202 & 4800 & 2560 & 9600 & 1536 & 1026 & 736 & 98 & 360 & 300 \\
\hline Start-up Energy (nJ) & 349 & $37 \dagger$ & 37 & 14 & $25 \dagger^{*} *$ & $35 \dagger$ & 20 & 9 & 4.4 & 3.7 \\
\hline Technique & $\begin{array}{c}\text { Chirped energy } \\
\text { injection }+ \\
\text { negative } \\
\text { resistance boost }\end{array}$ & $\begin{array}{l}\text { Dynamically } \\
\text { adjusted load } \\
+ \text { gm increase }\end{array}$ & $\begin{array}{l}\text { Negative } \\
\text { resistance } \\
\text { boost }\end{array}$ & $\begin{array}{c}\text { Negative } \\
\text { resistance } \\
\text { boost }\end{array}$ & $\begin{array}{l}\text { Dithered } \\
\text { energy } \\
\text { injection }\end{array}$ & $\begin{array}{c}\text { 2-step } \\
\text { energy } \\
\text { injection }\end{array}$ & $\begin{array}{l}\text { Multi-step } \\
\text { energy } \\
\text { injection }\end{array}$ & $\begin{array}{l}\text { Precisely } \\
\text { timed } \\
\text { injection }\end{array}$ & \multicolumn{2}{|c|}{$\begin{array}{l}\text { Self-timed } \\
\text { injection }\end{array}$} \\
\hline
\end{tabular}

* ESTIMATED BY MULTIPLYING STEADY-STATE POWER CONSUMPTION AND START-UP TIME $\dagger$ INCLUDING CLOCK BUFFER POWER

\section{CONCLUSION}

In this paper, a self-timed energy injection technique is proposed, enabling quick and energy efficient start-up of crystal oscillators. This is achieved by detecting the zero crossings of the motional branch current of the crystal, and using this information to switch the voltage over the crystal. Since the injection waveform is self-timed, the injection frequency automatically matches the crystal frequency. This allows accurate energy injection, without the need for power hungry frequency injection oscillators or calibration steps. The manufactured prototype achieves a start-up energy of $3.7 \mathrm{~nJ}$. To the authors' best knowledge, this the lowest start-up energy reported in literature so far.

\section{ACKNOWLEDGEMENTS}

The authors would like to thank Global Foundries for silicon donation, NXP for wire-bonding as well as Gerard Wienk and Henk de Vries from the University of Twente for their valuable $\mathrm{CAD}$ and measurement support.

\section{REFERENCES}

[1] K. Philips, "Ultra Low Power short range radios: Covering the last mile of the IoT," in ESSCIRC 2014 40th European Solid State Circuits Conference (ESSCIRC), 2014, pp. 51-58.

[2] J. Prummel et al., "A $10 \mathrm{~mW}$ Bluetooth Low-Energy Transceiver With On-Chip Matching," IEEE J. SolidState Circuits, vol. 50, no. 12, pp. 3077-3088, Dec. 2015.

[3] R. van Langevelde, M. van Elzakker, D. van Goor, H. Termeer, J. Moss, and A. J. Davie, "An ultra-lowpower 868/915 MHz RF transceiver for wireless sensor network applications," in 2009 IEEE Radio Frequency Integrated Circuits Symposium, 2009, pp. 113-116.

[4] Y. Chang, J. Leete, Z. Zhou, M. Vadipour, Y.-T. Chang, and H. Darabi, "A Differential Digitally Controlled Crystal Oscillator With a 14-Bit Tuning vol. 53, no. 3, pp. 692-702, Mar. 2018.

[9] D. Griffith, J. Murdock, and P. T. Roine, "5.9 A 24MHz crystal oscillator with robust fast start-up using dithered injection," in 2016 IEEE International Solid-State Circuits Conference (ISSCC), 2016, pp. 104-105.

[10] S. Iguchi, H. Fuketa, T. Sakurai, and M. Takamiya, "Variation-Tolerant Quick-Start-Up CMOS Crystal Oscillator With Chirp Injection and Negative Resistance Booster," IEEE J. Solid-State Circuits, vol. 51, no. 2, pp. 496-508, Feb. 2016.

[11] S. A. Blanchard, "Quick start crystal oscillator circuit," in Proceedings of the 15th Biennial University/Government/ Industry Microelectronics Symposium, 2003, pp. 78-81.

[12] Yong-Il Kwon, Sang-Gyu Park, Ta-Joon Park, KoonShik Cho, and Hai-Young Lee, "An Ultra Low-Power CMOS Transceiver Using Various Low-Power Techniques for LR-WPAN Applications," IEEE Trans. Circuits Syst. I Regul. Pap., vol. 59, no. 2, pp. 324-336, Feb. 2012.

[13] K.-M. Lei, P.-I. Mak, M.-K. Law, and R. P. Martins, “A Regulation-Free Sub-0.5-V 16-/24-MHz Crystal Oscillator With 14.2-nJ Startup Energy and $31.8 \mu \mathrm{W}$ Steady-State Power," IEEE J. Solid-State Circuits, vol. 53, no. 9, pp. 2624-2635, Sep. 2018.

[14] K. M. Megawer et al., "18.5 A 54MHz Crystal Oscillator With 30× 18.5 Start-Up Time Reduction Using 2-Step Injection in 65nm CMOS," in 2019 IEEE International Solid- State Circuits Conference (ISSCC), 2019, pp. 302-304.

[15] B. Verhoef, J. Prummel, W. Kruiskamp, and R. Post, "18.6 A 32MHz Crystal Oscillator with Fast Start-up Using Synchronized Signal Injection," in 2019 IEEE International Solid- State Circuits Conference (ISSCC), 2019, pp. 304-305.

[16] M. Ding, Y.-H. Liu, P. Harpe, C. Bachmann, K. Philips, and A. Van Roermund, "A Low-Power Fast Start-Up Crystal Oscillator With an Autonomous Dynamically Adjusted Load," IEEE Trans. Circuits Syst. I Regul. 
Pap., vol. 66, no. 4, pp. 1382-1392, Apr. 2019.

[17] M. Miyahara, Y. Endo, K. Okada, and A. Matsuzawa,

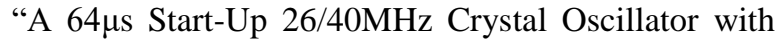
Negative Resistance Boosting Technique Using Reconfigurable Multi-Stage Amplifier," in 2018 IEEE Symposium on VLSI Circuits, 2018, pp. 115-116.

[18] E. A. Vittoz, M. G. R. Degrauwe, and S. Bitz, "Highperformance crystal oscillator circuits: theory and application," IEEE J. Solid-State Circuits, vol. 23, no. 3, pp. 774-783, Jun. 1988.

[19] A. Rusznyak, "Start-up time of CMOS oscillators," IEEE Trans. Circuits Syst., vol. 34, no. 3, pp. 259-268, Mar. 1987.

[20] K.-M. Lei, P.-I. Mak, and R. P. Martins, "A 0.4V $4.8 \mu \mathrm{W} 16 \mathrm{MHz}$ CMOS crystal oscillator achieving 74fold startup-time reduction using momentary detuning," in 2017 IEEE International Symposium on Circuits and Systems (ISCAS), 2017, pp. 1-4.

[21] H. Esmaeelzadeh and S. Pamarti, "A precisely-timed energy injection technique achieving 58/10/2 $\mu$ s start-up in $1.84 / 10 / 50 \mathrm{MHz}$ crystal oscillators," in 2017 IEEE Custom Integrated Circuits Conference (CICC), 2017, pp. 1-4.

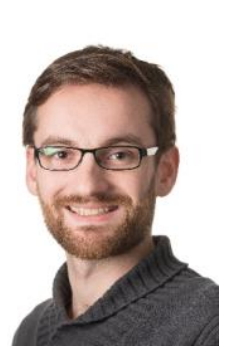

Joeri B. Lechevallier (S'15) received the B.Sc. and M.Sc. (cum laude) in Electrical Engineering from the University of Twente, Enschede, the Netherlands in 2012 and 2014, respectively, where he is currently pursuing his Ph.D. degree at the Integrated Circuit Design group. His current research interests include (ultra) low-power oscillators and RF receivers.

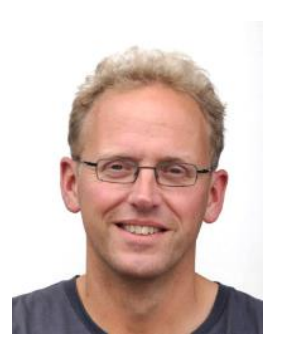

Ronan A.R. van der Zee (M'07) received the M.Sc. (cum laude) degree in electrical engineering and the Ph.D. degree in high efficiency audio amplifiers from the University of Twente, Enschede, The Netherlands, in 1994 and 1999, respectively. In 1999 he joined Philips Semiconductors, where he worked on class $\mathrm{AB}$ and class $\mathrm{D}$ audio amplifiers. In 2003, he joined the IC-Design Group, University of Twente. His research interests include linear and switching power amplifiers, RF frontends and ultralow power radio.

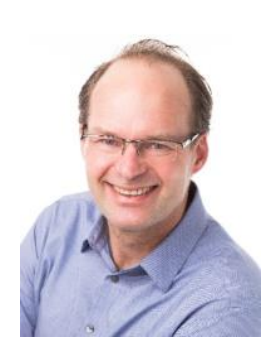

Bram Nauta (S'89-M'91-SM'03-F'08) was born in 1964 in Hengelo, The Netherlands. In 1987 he received the M.Sc degree (cum laude) in electrical engineering from the University of Twente, Enschede, The Netherlands. In 1991 he received the Ph.D. degree from the same university on the subject of analog CMOS filters for very high frequencies. In 1991 he joined the Mixed-Signal Circuits and Systems Department of
Philips Research, Eindhoven the Netherlands. In 1998 he returned to the University of Twente, where he is currently a distinguished professor, heading the IC Design group. Since 2016 he also serves as chair of the EE department at this university. His current research interest is high-speed analog CMOS circuits, software defined radio, cognitive radio and beamforming.

He served as the Editor-in-Chief (2007-2010) of the IEEE Journal of Solid-State Circuits (JSSC), and was the 2013 program chair of the International Solid State Circuits Conference (ISSCC). He is currently the President of the IEEE Solid-State Circuits Society (2018-2019 term).

Also, he served as Associate Editor of IEEE Transactions on Circuits and Systems II (1997-1999), and of JSSC (2001-2006). He was in the Technical Program Committee of the Symposium on VLSI circuits (2009-2013) and is in the steering committee and programme committee of the European Solid State Circuit Conference (ESSCIRC). He served as distinguished lecturer of the IEEE, is co-recipient of the ISSCC 2002 and 2009 "Van Vessem Outstanding Paper Award" and in 2014 he received the 'Simon Stevin Meester' award (500.000€), the largest Dutch national prize for achievements in technical sciences. He is fellow of the IEEE and member of the Royal Netherlands Academy of Arts and Sciences (KNAW). 